
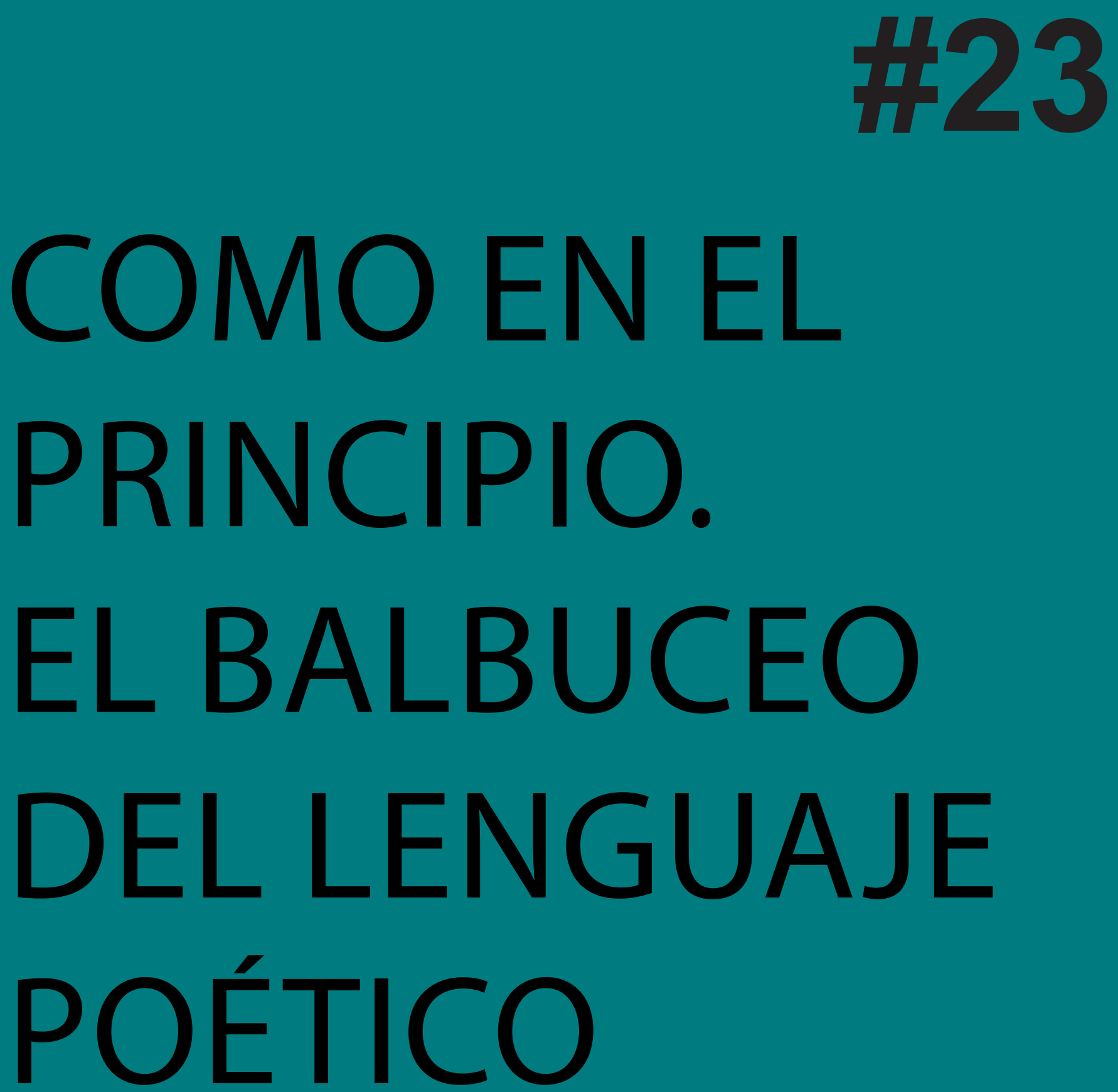

\title{
Eduardo Pellejero
}

Universidad Federal de Rio Grande do Norte (Brasil) 


\section{6=}

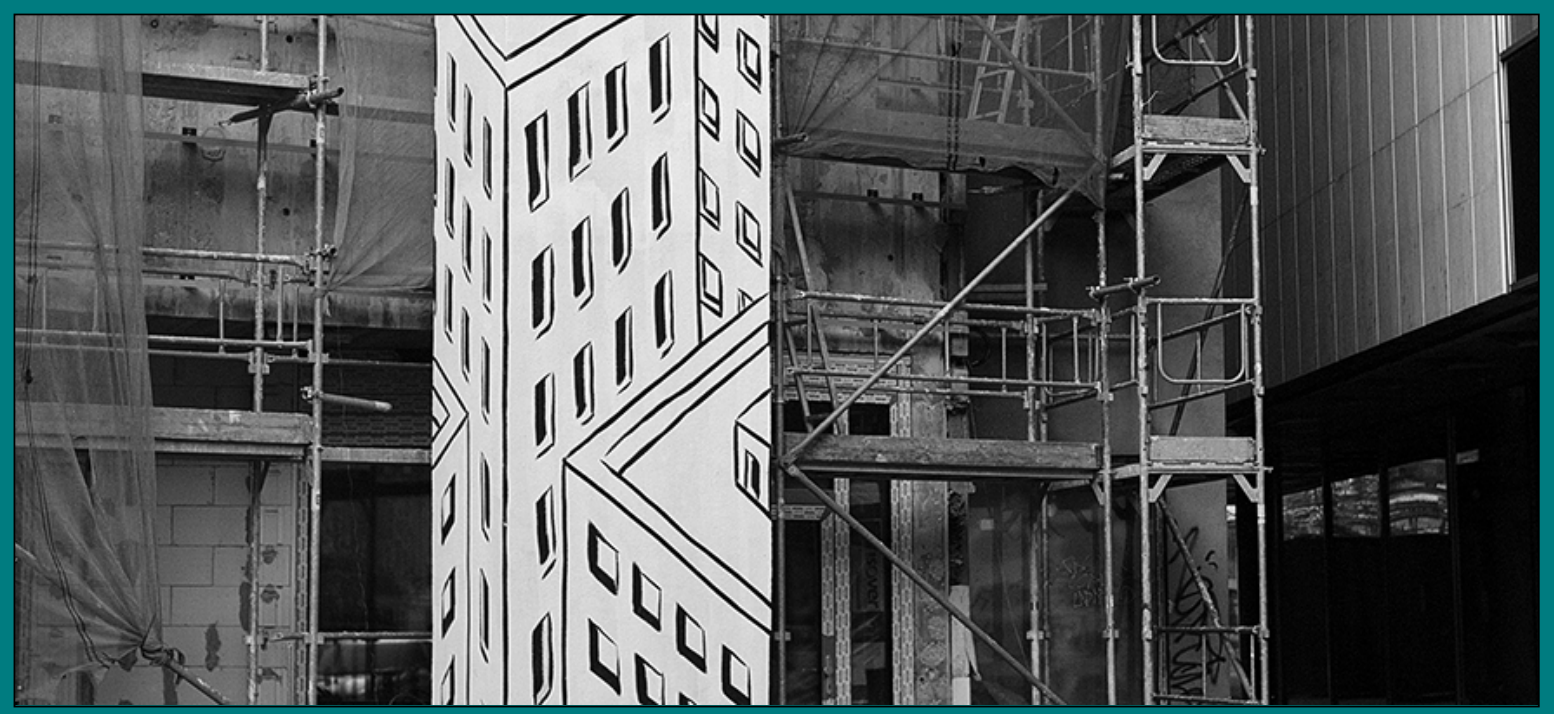

Resumen || Todos los escritores buscan algo, incluso cuando no siempre sepan lo que buscan. De sus obras siempre esperamos y retenemos algunos hallazgos, pero sobre todo estimamos la perseverancia en el ejercicio de nombrar y renombrar el mundo, que es prerrogativa de nuestra libertad. Nacimiento continuado, la literatura sacude o hace tartamudear la lengua, desconociendo el ascendiente de sus orígenes y exponiendo el lenguaje al riesgo de su suspensión -y quizás también a la posibilidad del recomienzo- El presente trabajo pretende explorar algunas de las singularidades del lenguaje poético en cuanto expresión creadora, a partir de un diálogo con las obras de Maurice Merleau-Ponty, Michel Foucault y Gilles Deleuze.

\section{Palabras clave || Lenguaje poético | Balbuceo | Expresión creadora | Merleau-Ponty}

Abstract ||All writers are looking for something, even though they may not always know what that something is. From their works, we expect and keep some discoveries, but mainly we value their perseverance in the exercise of naming and renaming the world, which is a prerogative of our freedom. Literature shakes language, or makes it stutter, exposing its structures to the risk of suspension -and perhaps, also, to the chance of a new beginning - . This paper aims to explore some singularities of poetic language as creative expression, establishing a dialogue with the works of Maurice Merleau-Ponty, Michel Foucault and Gilles Deleuze.

\section{Keywords || Poetic Language | Babbling | Creative expression | Merleau-Ponty}

Resum || Tots els escriptors busquen alguna cosa, fins i tot quan no sempre sàpiguen el que busquen. De les seves obres sempre esperem i retenim algunes troballes, però sobretot estimem la perseverança en l'exercici de nomenar i canviar de nom el món, que és prerrogativa de la nostra llibertat. Naixement continuat, la literatura sacseja o fa quequejar la llengua, desconeixent l'ascendent dels seus orígens i exposant el llenguatge al risc de la seva suspensió -i potser també a la possibilitat del recomençament-. El present treball pretén explorar algunes de les singularitats del llenguatge poètic com a expressió creadora, a partir d'un diàleg amb les obres de Maurice Merleau-Ponty, Michel Foucault i Gilles Deleuze.

Paraules clau || Llenguatge poètic | Balboteig | Expressió creadora | Merleau-Ponty 
Hemos aprendido no a hablar, sino a balbucear, y únicamente prestando oído al ruido creciente del mundo, $y$, una vez blanqueados por la espuma de su cresta, hemos adquirido una lengua.

Osip Mandelshtam

Max Aub decía que el único pecado para un escritor es no sentir que está como en el principio (incluso del lenguaje). Esto es así porque la literatura es una búsqueda. Todos los escritores buscan algo, incluso cuando no sepan lo que buscan ${ }^{1}$. De sus obras esperamos y retenemos algunos descubrimientos, pero sobre todo la ambición prometeica de renombrar el mundo, que es la prerrogativa de nuestra libertad².

La filosofía siempre especuló sobre el origen del lenguaje. Más recientemente, la ciencia moderna creyó poder encontrarlo literalmente en alguno de los rincones del cerebro y desvendar su secreto sin sombras. Sin embargo, tal vez sea posible asistir a su nacimiento de una forma al mismo tiempo más simple y más directa, porque con cada frase, con cada palabra de cada frase, la literatura es la potencia de ese gesto inaugural, donde las cosas se desconocen a sí mismas y el mundo se asombra del mundo.

No puedo dejar de recordar que Noam Chomsky, siempre que es interrogado sobre el lenguaje de la poesía, se excusa aludiendo a la opacidad del lenguaje literario y su incompetencia en la materia ${ }^{3}$. Esto siempre me pareció extraordinario: que Chomsky, que opinaba sobre todo, no se atreviera a tejer tesis sobre la literatura.

Por su parte, Gilles Deleuze, que no despreciaba las ciencias, se lamentaba de que los estudios sobre el lenguaje estuviesen invariablemente enfocados en los fenómenos de comunicación y no prestasen atención, o casi no prestasen atención, a esos acontecimiento singulares sin los cuales ni siquiera el propio lenguaje sería posible: las manifestaciones de la expresión creadora ${ }^{4}$, donde el lenguaje no se comporta como un medio de codificación y decodificación para significaciones disponibles, sino que asume la tarea de producir significaciones a partir de una experiencia no pautada del mundo (Merleau-Ponty, 1991: 43).

Lo cierto es que cada vez que la literatura conmueve el lenguaje, esto es, cada vez que suspende sus poderes y coloca entre paréntesis su valor de verdad para hacerlo balbucear palabras nunca antes pronunciadas, la mente humana vuelve a entrar en la caverna ${ }^{5}$. «La impronta del poeta [...] retoma y reinventa a su manera el grito de los orígenes» (Merleau-Ponty, 1974: 68 - modificado).

Evidentemente, el lenguaje no funciona ni siempre ni la mayoría de las veces de esa forma. Moneda depositada en silencio en la

\section{NOTAS}

1 | Merleau-Ponty (2004: 138) recuerda que Balzac coloca en boca de Louis Lambert, genio fracasado de La comedia humana, estas palabras: «Camino para algunos descubrimientos».

2 | «Todo acto de expresión literaria o filosófica contribuye para cumplir el voto de recuperación del mundo que fue pronunciado con el aparecimiento de una lengua, esto es, de un sistema finito de signos que en principio se pretendía capaz de captar cualquier ser que se presentase. En lo que le concierne, realiza una parte de ese proyecto y prorroga el pacto que acaba de llegar al vencimiento abriendo un nuevo campo de verdades» (MerleauPonty, 1991: 102).

3 | Ver, por ejemplo, la entrevista de Chomsky con Al Page en la Universidad de Washington (1989): $<$ https://www.youtube.com/ watch?v=hdUbllwHRkY>.

\section{4 | Por su vez, Merleau- Ponty decía: dejar esto de la expresión (y los secretos del nacimiento del sentido y del lenguaje) en manos de los psicólogos es como dejar dinamita en manos de niños.}

5| Estuvimos muchas veces ahí, solos, en lo alto de la noche, casi a oscuras, en el secreto de nuestras habitaciones. 
palma de nuestra mano, se encuentra ordinariamente al servicio del comercio que tendemos a confundir con la praxis. Quizás, como constatan actualmente los lingüistas, entonces el lenguaje se preste al cálculo.

Cuando, por el contrario, el lenguaje es solidario de la expresión creadora ${ }^{6}$, cuando es exploración de lo que se agita en nuestra intimidad o asombra al mundo, esto es, cuando se impone a la habladuría y se confronta con el silencio fascinado del que proviene, cuando nos deja sin palabras y permite escuchar el rumor inmemorial al que se remonta continuamente todo intento de extraer de lo real un poco de sentido -entonces el lenguaje poético es «un nacimiento continuado» y no admite reducción?.

Hace unos años fue encontrada en una gruta de Stadel, Alemania, una escultura de marfil de más de 32000 años de antigüedad. El cuerpo es humano, la cabeza de león. Constituye uno de los primeros ejemplos de la capacidad humana para imaginar cosas que no existen, esto es, para traer lo nuevo al mundo y poblar de formas inéditas el universo.

Todos los animales, al parecer, poseen alguna forma de lenguaje (hasta los insectos). Algunos, como los monos, poseen incluso un lenguaje vocal que en algunos aspectos se asemeja al nuestro. Los zoólogos han identificado, por ejemplo, entre los monos-verdes, gritos que sirven para comunicar diversos peligros. Así, un grito significa «icuidado, un águila!» y otro, diferente, «icuidado, un león!».

Un ser humano puede decir, además, que por la mañana, cerca de la curva del río, vio un león atrás de una manada de bisontes, y describir la localización exacta, incluyendo los caminos que conducen al lugar (permitiendo trazar un plan para acercarse al río, espantar al león y cazar los bisontes). También puede hablar de otros hombres y mujeres, incluso cuando no se encuentren presentes (chisme). Pero sobre todo es capaz de expresar, no apenas lo que es, sino también lo que no es, lo que podría ser —esto es, lo que late en su pecho o asombra sus sueños- ${ }^{9}$. El ser humano es, en virtud de esa rara potencia del lenguaje que habla, un animal expresivo -o un animal literario, como dice Rancière (2005: 59) ${ }^{10}$.

Esta singularidad, que fue propiciada por la naturaleza ${ }^{11}$, de alguna manera nos emancipa de la naturaleza, porque es capaz de dar lugar a naturalezas segundas (a nuevas formas y configuraciones de lo humano). A través del lenguaje, con efecto, podemos poner en causa nuestra constitución histórica y contribuir para lo que Hegel llamaba el devenir de la conciencia ${ }^{12}$, rearticulando lo dado, resignificando nuestra experiencia y expresando creativamente

\section{NOTAS}

6 | «Distinguimos el uso empírico del lenguaje ya elaborado y el uso creador, del cual el primero solo puede ser un resultado» (Merleau-Ponty, 1991: 45).

7 | luri Lotman (1978: 30) decía que la literatura era «una fabulosa generadora de lenguaje».

8| Sobre estas cuestiones, ver: Robin Dunbar, Grooming, Gossip, and the Evolution of Language, Londres: Harvard University Press, 1998; Arnold, K., Pohlner, Y., \& Zuberbühler, K., «A forest monkey's alarm call series to predator models», en: Behavioral Ecology and Sociobiology, 62(4), 2008 : 549-559; Arnold, K., \& Zuberbühler, K., «Semantic combinations in primate calls", en: Nature, 441(7091), 2006; Cheney, D. L., \& Seyfarth, R. M., How monkeys see the world, Chicago: IL: University of Chicago Press, 1990.

9 | Una introducción simple al estado de los estudios sobre estas cuestiones, accesible a legos, puede encontrarse en: Yuval Noah Harari,

Sapiens. Uma breve história da humanidade, São Paulo: L\&PM, 2015.

10| En un estudio de 1955 dedicado al pensamiento de Hegel (y de Kojéve), Georges Bataille ya afirmaba que lo que distingue al hombre del animal es la ficción, tejida en la distancia que nos separa de lo real, de la necesidad y de la muerte. Sobre ese singular plano expresivo somos capaces de afirmar lo que no es, tal como es, y construir, más allá de las exclusiones que define lo que se presenta como verdadero para una época dada, la trama de otros mundos posibles (Bataille,

2013: 405).

11| Sobre esto ver Henri 
nuestra relación con el mundo y con los otros — son cosas que están en el corazón de lo que somos (de nuestra libertad).

Maurice Merleau-Ponty fue sin dudas uno de los pensadores que más profundamente indagó en los secretos del nacimiento del sentido y del lenguaje, que eran para él los secretos del sentido y del lenguaje nacientes tal como se manifiestan, por ejemplo, en la literatura - «momento fecundo en que las palabras dan forma a la experiencia, en que un sentido que era apenas latente encuentra los emblemas que lo liberarán y lo tornarán manejable para el artista y accesible a los otros» (Merleau-Ponty, 1974: 71 - modificado).

En un texto de 1952, Merleau-Ponty relata su asombro ante una película que mostraba, en cámara lenta, el prodigioso trabajo de Henri Matisse. Al parecer, el propio Matisse quedara conmovido al ver que su pincel meditaba, «en un tiempo dilatado y solemne, en una inminencia de comienzo del mundo, intentando diez movimientos posibles, danzando ante la tela, rozándola varias veces, hasta por fin abatirse como un rayo sobre el único trazado necesario» (MerleauPonty, 1974: 46-47).

La crítica, influenciada por el estructuralismo, intentó muchas veces colocarse en la posición de esa cámara, desde donde el lenguaje aparece como un espacio de permutación entre posibles y la obra como una elección a ser justificada o comparada con otras elecciones posibles ${ }^{13}$. Sucede, no obstante, que la duda de Matisse es antes signo de la contingencia radical de todo lenguaje naciente y que las palabras no se buscan como se busca un martillo para clavar un clavo, ni mucho menos como una solución entre otras en un juego sin consecuencias ${ }^{14}$. La escritura, por ejemplo, en cuanto movimiento singular del lenguaje poético, es, antes, un tanteo, un gesto cuya significación solo se revela a posteriori, en los textos a los que da lugar ${ }^{15}$.

Intentando caracterizar la naturaleza impropia de esa forma de la expresión creadora, Deleuze decía: el escritor tartamudea ${ }^{16}$; Merleau-Ponty propone sacudir el aparato del lenguaje. En todo caso, cuando la palabra, por fin, gana una articulación efectiva, suena, incluso a los oídos del propio escritor, como una palabra nunca antes oída, nueva, inaugural. «El artista [...] no se contenta con ser un animal cultivado, él asume la cultura desde su comienzo y la funda nuevamente, habla como el primer hombre habló y pinta como si jamás hubiesen pintado» (Merleau-Ponty, 2004: 139).

Aunque, como irónicamente recordaba Michel Foucault (2000: 163), la literatura está hecha de lenguaje y la palabra siempre tiene lugar sobre un fondo de palabra (Merleau-Ponty, 1991: 42), su muy

\section{NOTAS}

Bergson, Les deux sources de la morale et la religion, Paris: Puf, 1984.

12 | Por su vez, «la literatura habla un lenguaje particular que se sobrepone a la lengua natural como sistema secundario» (Lotman, 1978: 55), pero que no por eso deja de ser capaz de operar sobre el lenguaje común. En el fondo, no hay lengua originaria y la literatura es el lugar donde mejor se procede al olvido de los orígenes.

13| «Considerando el lenguaje como hecho consumado, residuo de actos de significación pasados, el científico deja escapar la claridad propia del habla, la fecundidad de la expresión» (Merleau-Ponty, 1991: 91).

14 | «Ningún lenguaje se separa totalmente de la precariedad de las formas de expresión mudas, no reabsorbe la propia contingencia» (Merleau-Ponty, 1991: 83).

15 | «El propio autor no tiene ningún texto que pueda confrontar con su escrito, ningún lenguaje antes del lenguaje. Si sus palabras lo satisfacen, es por un equilibrio cuyas condiciones ella propia define, por una perfección sin modelo. [...] Como el tejedor, el escritor trabaja por el revés: lidia apenas con el lenguaje, y es así que de repente se encuentra rodeado de sentido» (Merleau-Ponty, 1991: 43 y 45).

16 | Proust decía: «las obras maestras están escritas en una especie de lengua extranjera». Es lo mismo que tartamudear, pero siendo tartamudo del lenguaje y no simplemente de la palabra. Ser extranjero, pero en su propia lengua, y no simplemente como alguien que habla una lengua que no es la suya. Ser 
particular manera de poner en juego el lenguaje hace que las palabras funcionen menos como signos que como una forma de materia sutil - «el mínimo de materia de que un sentido tiene necesidad para manifestarse en las cosas» (Merleau-Ponty, 1974: 61)—17. Luego, la literatura es de alguna forma un poder espiritual, que desdobla un universo capaz de alojar en sí las propias cosas o establece un lazo entre el hombre y el mundo, entre la subjetividad y los objetos ${ }^{18}$ -transposición aproximativa, indirecta, alusiva, nunca completa, en una lengua extraña, pero capaz de tornar la experiencia significante sin ocultar el fondo asignificante sobre el que tiene lugar.

Para eso, la literatura transmuta el sentido disperso en la experiencia, movilizando en su provecho instrumentos ya revestidos — por el uso- de una significación común: palabras, formas, giros, sintaxis, e inclusive géneros literarios, maneras de contar (Merleau-Ponty, 1974: 62). En ese expediente, no duda en cuestionar todo el orden de la significación para alcanzar aquello que escapa al lenguaje; «en el límite, es posible que ninguna de las palabras de la literatura tenga exactamente el sentido que damos a las mismas palabras que pronunciamos cotidianamente, es posible que la palabra suspenda el código del cual fue tomada» (Foucault, 2000: 159).

La literatura conserva destruyendo e interpreta deformando. Antes de constituirse como representación de una realidad cualquiera, opera una «metamorfosis del mundo percibido (confuso e incierto) en un universo significante (ficcional o lírico)» (Merleau-Ponty, 1974: 67); metamorfosis del mundo en el hombre, en cuanto cosa humana, decía Nietzsche (2001: 15), pero también «respuesta a aquello que el mundo, el pasado, las obras anteriores le pedían —consumación, fraternidad» (Merleau-Ponty, 1974: 80).

Eso quiere decir que lo propio del lenguaje literario no es dar preferencia a lo subjetivo sobre lo objetivo, a lo individual sobre lo universal, o a lo no-significante sobre lo significante. En última instancia, el poeta, ocupado en expresar el sentido de su experiencia, «nada sabe de la antítesis del hombre y del mundo» (Merleau-Ponty, 1991: 55).

La literatura no es la mera exposición de fantasías noveladas, de creencias, ilusiones o ideologías, sino un tratamiento específico del mundo - no un tratamiento opuesto al trato de lo verdadero, sino un trato diferencial, que complica todo el orden del discurso, a través de transposiciones, metáforas y metonimias, «manifestando el deseo de dar al mundo - tal como este es a los ojos del hombre despierto, tan diverso, irregular, vano e incoherente -una forma siempre nueva» (Nietzsche, 2001: 19).

\section{NOTAS}

bilingüe, multilingüe, pero en una sola y misma lengua, sin ni siquiera dialecto o patois. Ser un bastardo, un mestizo, pero por purificación de la raza. Ahí es donde el estilo crea lengua. Ahí es donde el lenguaje deviene intensivo, puro continuum de valores y de intensidades. Ahí es donde toda la lengua deviene secreta $y$, sin embargo, no tiene nada que ocultar, en lugar de crear un subsistema secreto en la lengua. A ese resultado solo se llega por sobriedad, sustracción creadora. La variación continua solo tiene líneas ascéticas, un poco de hierba y de agua pura» (Deleuze-Guattari, 1980: 123125).

17 | En una nota al margen muy sugestiva, Merleau-Ponty se pregunta: «Metensomatosis del arte. ¿Qué es transportado?».

18 | Lazo elusivo y precario (se trata, apenas, de una relación estética), pero fundamental. 
Al mismo tiempo, porque la percepción nunca está acabada, y porque la articulación significante del mundo comporta un trabajo infinito ${ }^{19}$, el lenguaje poético hace oír su ascendente bajo las formas del lenguaje corriente -apelando a nuestra potencia de expresar más allá de lo visto y lo pensado, de lo dicho y lo experimentado. El lenguaje, decía Merleau-Ponty (1991: 53), es preciso que sea poesía.

La aventura que comporta la literatura, por tanto, excede largamente los cálculos de la actividad significante. Tiene lugar en la distancia que va de lo que vivimos o experimentamos a lo que es o ya fue dicho y pensado, escrito o pronunciado - o es esa distancia, cavada en el interior del propio lenguaje, exponiéndolo, dispersándolo, trabajándolo (Foucault, 2000: 142) ${ }^{20}$.

Ningún camino regular conduce de la incandescente multiplicidad de la experiencia al orden de la significación, pero las operaciones poéticas parecen dotar al escritor «de nuevos órganos» (MerleauPonty, 1974: 71), de una extraña sensibilidad por la cual es capaz de percibir el exceso de lo que hay por decir sobre los poderes ordinarios del lenguaje ${ }^{21}$. De ahí que la temporalidad en la cual trabaja no se adecue a la fugacidad de los actos ilocutorios cotidianos, sino que se abra a una "eternidad siempre por rehacer» donde encuentra y coloca en causa, abraza y transfigura «toda una serie de expresiones anteriores sedimentadas» (Merleau-Ponty, 1974: 98).

Merleau-Ponty (1974: 76) dice que la poesía hace arder el lenguaje ordinario, en un sentido que recuerda inevitablemente los juegos ardientes de la ficción de los que hablaba Foucault (1994: 506). Eso significa que sus palabras subvierten e indeterminan, impugnan y ponen en variación el lenguaje hablado y, en general, los regímenes del lenguaje en sus más diversas órdenes del discurso ${ }^{22}$. Colocan al descubierto, «bajos los enunciados y su ruido sabiamente ordenados a significaciones bien definidas, un lenguaje operante o hablante cuyas palabras viven una vida secreta como los animales de las grandes profundidades» (Merleau-Ponty, 1974: 98). Debajo del desorden que producen sus excentricidades sintácticas y ortográficas, su indocilidad semántica y su inclinación a lo asignificante, y también su falta de respeto por los lugares de enunciación asignados y su ignorancia programática de las relaciones instituidas entre las palabras y las cosas, revelan siempre algo más ${ }^{23}$. Juan José Saer acostumbraba decir que no se escribe literatura para esquivar, por inmadurez o irresponsabilidad, los rigores que exige el tratamiento de la «verdad», sino justamente para poner en evidencia el empobrecimiento de la realidad que imponen los modos instituidos de ejercer el lenguaje; escribir «multiplica las posibilidades de tratamiento de lo real, se sumerge en su turbulencia, desdeñando la actitud ingenua que consiste en pretender saber de antemano cómo

\section{NOTAS}

19 | «La expresión de aquello que existe es una tarea infinita» (Merleau-Ponty, 2004: 134).

20 | «El escritor, sin transiciones ni preparativos, nos transporta del mundo ya dicho para otra cosa» (Merleau-Ponty, 1991: 82).

21 | Para un artista, escribe Merleau-Ponty (2004: 138), una única emoción es posible: «el sentimiento de extrañeza», y un único lirismo: «el de la existencia siempre recomenzada».

22 | La literatura no se distingue para Foucault por las historias que cuenta, sino por la torsión que impone al lenguaje y por el espacio de variación que abre al nivel de la enunciación. De ahí que desde el momento en que tiene lugar, con cada palabra escrita o pronunciada, pueda 1) comprometer el lenguaje, y 2) transgredir el orden del discurso.

23 | «Otro orden, un nuevo sistema de equivalencias [que] exige esa subversión [...] en nombre de una relación más verdadera entre las cosas» (Merleau-Ponty, 1974: 76). Un poeta tiene por tarea, definitivamente, traducir esas palabras, esa voz, ese acento cuyo eco cada cosa o cada circunstancia le envía. No hay cambio en el lenguaje ordinario ante el cual retroceda para llevar a cabo su tarea, pero no propone ningún cambio que no sea motivado. 
está constituida esa realidad y cuáles son las formas adecuadas de su representación» (Saer, 2004: 11) ${ }^{24}$.

Ningún escritor ignora que, incluso cuando la lengua ofrezca más de lo que habríamos sabido encontrar por nosotros mismos, todo está aún por ver, por pensar y por hacer, y que es siempre preciso reinventar el lenguaje en el interior del lenguaje. «Los bellos libros están escritos en una especie de lengua extranjera» (Proust, 1971: 305). El lenguaje, tal como se dispone a un sujeto cualquiera en la hora de dar forma y sentido a la experiencia, constituye apenas un punto de partida o, mejor, un punto de inflexión en las aventuras de la expresión. Como saben los poetas, «la existencia de una lengua dada nos oculta más de lo que nos revela la verdadera función de la palabra» (Merleau-Ponty: 120). La comprensión del mundo y de los otros no se encuentra dada a priori, depositada en el tesoro de la lengua, sino que se promete a aquellos decididos a ir hasta el final en la selva de las cosas y de los signos - a aquellos que, superando el silencio que parece imponernos la experiencia cuando excede sus límites habituales, tienen el coraje de responder de manera creativa, por metáforas prohibidas y encadenamientos conceptuales inauditos, destruyendo las viejas barreras (Nietzsche, 2001: 20).

Ahora, «el hombre que escribe, si no se contenta con dar continuidad al lenguaje que recibió, o en volver a decir cosas ya dichas, no quiere tampoco substituirlas por un idioma que [...] sea cerrado sobre su propia significación» (Merleau-Ponty, 1974: 109). Ni la poesía ni la literatura fueron nunca la fantasía de un lenguaje privado. El recomienzo perpetuo, que es la cifra en la cual reconocemos su intimidad con la expresión creadora, no es una hecatombe, un holocausto, sino parte de una dialéctica sin resolución posible, donde el lenguaje es sacrificado y consagrado al mismo tiempo, destruido y realizado: destruido en tanto «habla lista, que no despierta más en nosotros otra cosa que significaciones debilitadas, y no torna presente lo que dice»; realizada en la medida en que «la lengua dada que penetra [al escritor] de parte a parte y ya ofrece una figura general a sus pensamientos más secretos, no está ahí como una enemiga, sino enteramente lista para convertir en adquisición lo que él significa de nuevo» (Merleau-Ponty, 1974: 110).

En el fondo, no basta romper el lenguaje para escribir una gran obra. Negar por la escritura el orden de las significaciones ordinarias solo se suma al movimiento de la literatura cuando su objeto último pasa por el retorno de esas significaciones en nuevas configuraciones de sentido - en una «visión sin viseras» que, sin ideas preconcebidas, «descentra y reagrupa los objetos del mundo o de las palabras» (Merleau-Ponty, 1974: 77) -. Por la literatura el mundo es sometido a un principio de anamorfosis siempre singular (a una deformación coherente) ${ }^{25}$. Esa metamorfosis conmueve el lenguaje y lo coloca

\section{NOTAS}

24 | No un tratamiento opuesto al trato de lo verdadero, sino un tratamiento diferencial. Si hay en el hombre un instinto que lo impulsa a la creación de metáforas, como pensaba Nietzsche, el mismo no se encuentra sometido a la voluntad de verdad. Maurice Blanchot (2011: 261), por ejemplo, atribuye a la literatura una forma esencial de la autenticidad que no tendría la forma de lo verdadero. Merleau-Ponty (1991: 59), que tiene presente la provocación sartreana de que es necesario mentir para ser verdadero, coloca la cuestión en términos de «una verdad que no se asemeje a las cosas, que no tenga modelo exterior, ni instrumentos de expresión predestinados, y que sea con todo verdad». En un mismo movimiento, la literatura se substrae a lo verdadero y dispersa el lenguaje. Luego, no dice simplemente lo falso, lo meramente errado, lo fantástico o lo irreal. Dice más que lo verdadero (dice la cosa y dice la distancia que separa y aproxima al lenguaje de la cosa), y dice menos que la verdad (dice la cosa sin presuponer la posibilidad de una adecuación entre las palabras y las cosas). En ese sentido, el ejercicio de la literatura implica un desplazamiento fundamental en relación a los discursos que reclaman de derecho la propiedad de la verdad y de lo verdadero, porque asumiendo su diferencia no denuncia apenas la injusticia de esos discursos, sino que asume al mismo tiempo el sistema de su propia injusticia. «No es una claudicación ante esta o aquella ética de la verdad, sino la búsqueda de una menos rudimentaria» (Saer, 2004: 11).

25 | En última instancia, el lenguaje poético no es simplemente una reivindicación del silencio, de la misma forma que no es un mero 
en peligro, pero también lo abre siempre a nuevas configuraciones (y ese lenguaje es tanto herencia como tarea para nosotros).

En resumen, nuestros actos expresivos tienden a superar el lenguaje del cual nos valemos en dirección a otro lenguaje - quizá en dirección a un lenguaje "destinado a ser por siempre un sueño de lenguaje» (Nancy, 2015: 66), en la medida en que se trata de conducir siempre más lejos las experiencias_-26. Y, como señala Jean-Luc Nancy (2015: 62), el naufragio de ese lenguaje está siempre garantizado: su abertura radical ${ }^{27}$, que escapa a cualquier medida, fuera de la medida que impone su forma, lo condena a perderse, a diluirse en el mismo lenguaje que contorna y tuerce, que enrarece y alimenta (solo que ese lenguaje ya no es el mismo y, balbuceante, se dirige a aquello que no tomó todavía la palabra: al lector o al mundo).

Evidentemente, de la misma forma que no todo ser que viene al mundo lo inaugura, no toda obra renueva el lenguaje, lo refunda, pero comporta en sí, siempre, la potencia de hacerlo: «la palabra literaria tiene siempre el derecho soberano de suspender el código, y es la presencia de esa soberanía, incluso si no es ejercida, que constituye el peligro y la grandeza de toda obra literaria» (Foucault, 2000: 159). Resta saber si ese «esfuerzo abortado para decir algo que permanece siempre por decir» (Merleau-Ponty, 1974: 109) que es propio de la literatura no constituye en última instancia lo propio del lenguaje en general.

Gesto que se apoya en el mundo y que al mismo tiempo se separa de él, conducta idiosincrática que sueña con ser objeto de un asentimiento universal ${ }^{28}$, con la comunicación o la comunión posible de los actos con los que damos consistencia y sentido a la experiencia y hacemos mundo, el lenguaje de la expresión creadora es siempre un salto del lenguaje en el vacío de las significaciones ya dadas ${ }^{29}$.

De ahí que uno de los problemas de la literatura sea saber cómo la intención del escritor renacerá en aquellos que leen sus textos, esto es, desvendar lo que acontece cuando el lector, interpelado por el texto, retoma por su cuenta el sentido del gesto que lo creó $y$, saltando los intermediarios, sin otra guía a no ser el ritmo y la sintaxis, los signos impresos sobre la página, alcanza el mundo balbuceante del escritor, a partir de entonces proferido claramente y accesible a todos y no importa quién (Merleau-Ponty, 1974: 64 y 68$)^{30}$. Quiero decir que, a pesar de la mediación del lenguaje, la deformación que la literatura opera en el lenguaje coloca siempre la cuestión de «cómo puede haber ahí una comunicación antes de la comunicación» (Merleau-Ponty, 1974: 69-70), sin modelo exterior ni instrumentos de expresión predestinados ${ }^{31}$.

\section{NOTAS}

sistema de comunicación. Incluso pudiendo funcionar de ambas formas, es, de forma más esencial, un modo de hacer mundos, una actividad modelizante (Lotman, 1978: 44).

26 | «El arte verbal, aunque se funde en la lengua natural, apenas se funda para transformarla en su propio lenguaje, secundario, el lenguaje del arte. $Y$ este "lenguaje del arte" es una jerarquía compleja de lenguajes interrelacionados pero no semejantes. A eso está ligada la pluralidad de principio de las lecturas posibles de un texto artístico. A eso también está ligada la carga significante, inaccesible a cualquier otro lenguaje no artístico» (Lotman, 1978: 58).

27 | «En cuanto a la literatura, en general acepta más resueltamente nunca ser total y darnos apenas significaciones abiertas» (Merleau-Ponty, 1974: 119).

28 | Merleau-Ponty (1991: 90) reconoce en la fenomenología de Hegel un antecedente de esa propiedad de todo lenguaje inaugural que, más allá de ser una manera original de considerar los objetos, constituye una operación por la cual pensamientos, que sin él permanecerían fenómenos privados, adquieren valor intersubjetivo. También dice que el artista retoma y convierte justamente en objeto sensible lo que sin él permanecería encerrado en la vida separada de cada conciencia (Merleau-Ponty, 2004: 137). «Una teoría física nueva puede ser probada porque la idea o sentido están ligados por el cálculo a medidas que son de un dominio común a todos los hombres. Un pintor, como Cézanne, un artista, un filósofo, deben no apenas crear y expresar una idea, 
Lo cierto es que, incluso cuando todo en una obra literaria sea recibido como habiendo sido elaborado ad hoc, de alguna forma aspira a llegar a formar parte de la experiencia de la humanidad, tornándose parte del lenguaje compartido, de tal forma que «lo que era un acaso de contenido para un determinado texto se torne un código para la posteridad» (Lotman, 1978: 53) ${ }^{32}$. Tal es el misterio del lenguaje poético - y también el del origen del lenguaje a secas-. Riesgo que hace pesar la literatura sobre la comunicación y que no es apenas un defecto provisorio del lenguaje del cual la crítica podría liberarnos por un trabajo de esclarecimiento, de desambiguación o fijación, sino «el precio que se debe pagar para tener un lenguaje conquistador, que no se limite a enunciar lo que ya sabíamos, sino que nos introduzca a experiencias extrañas, a perspectivas que nunca serán nuestras, y nos deshaga por fin de nuestros preconceptos » (Merleau-Ponty, 1974: 101 $)^{33}$.

Han pasado más de sesenta años desde que Merleau-Ponty articulara estas cuestiones. No es fácil entender, por tanto, que el estudio del lenguaje de la expresión creadora continúe siendo relegado a un segundo plano en nuestras instituciones universitarias. ¿No debería constituir, para comenzar, uno de los objetos principales de los estudios del lenguaje? ${ }^{34}$ ¿No es acaso la negligencia de ese fenómeno una de las razones de la distancia cada vez mayor entre la lingüística y la literatura comparada (en cuanto de un lado se estudia la organización del lenguaje, del otro se estudia su cuerpo)? ¿No habría lugar para sondar ese cuerpo antes de (o en proceso de) organizarse?

Si los estudios del lenguaje aceptasen ese desafío, lo que quizás solo sea posible como ciencia potencial de una universidad imaginaria, debería tratar el texto literario, no como objetos de análisis, como suma de signos o repertorio de ideas, sino como «nuevo órgano de la cultura humana que propicia, no un número finito de movimientos, sino un tipo general de conducta, abriendo un horizonte de investigaciones» (Merleau-Ponty, 1974: 82). Eso significa considerar el lenguaje poético como un lenguaje inaugural, que torna posible lo que no era posible antes de él, transfigurando el emprendimiento literario al mismo tiempo que lo realiza, así como destruye el lenguaje al mismo tiempo que lo expande, abriendo la literatura, el lenguaje y el mundo a un futuro indefinido ${ }^{35}$.

Para que la literatura pueda ser considerada de esa forma, en principio, es necesario no observar sus obras como objetos acabados, distinguiéndolas por su estilo y atribuyéndoles un falso prestigio, sino como gestos que se dirigen a nosotros y aguardan que les respondamos por apropiaciones transformadoras, en las cuales no apenas se encuentra en juego el sentido de nuestro pasado, sino también el de su porvenir. Tratarlas, en fin, no apenas como campo

\section{NOTAS}

sino también despertar las experiencias que la enraizarán en las otras conciencias. [...] Entonces, la obra de arte habrá juntado vidas separadas, no existirá más apenas en una de ellas como un sueño tenaz o un delirio persistente, o en el espacio como una tela colorida: ella habitará indivisa en varios espíritus, presumiblemente en todo espíritu posible, como una adquisición para siempre» (Merleau-Ponty, 2004: 140).

29 | Ese salto comporta para Merleau-Ponty (1991: 80) una especie de red de seguridad, en la medida en que «el novelista mantiene con su lector, así como todos los hombres con todos los hombres, un lenguaje de iniciados: iniciados en el mundo, en el universo de los posibles contenidos en un cuerpo humano, en una vida humana».

30 | «Gesto elocuente», resalta Merleau-Ponty (1991: 43).

31 | «Las palabras, en el arte de la prosa, transportan a aquel que habla y a aquel que escucha a un universo común, pero solo lo hace al arrastrarnos con ellas hacia una significación nueva, mediante una fuerza de designación que sobrepasa su definición o significación aceptada» (Merleau-Ponty, 1974: 98). La literatura, en ese sentido, en cuanto manifestación privilegiada del lenguaje poético, no constituye una simple manera (entre otras) de representar, comunicar o significar lo dado, sino la invención, la inauguración y la expresión de lo no dado (MerleauPonty, 1974: 69). En el fondo, comprometiendo el poder de expresar y de comprender que es propio del ser humano, ofrece una consistencia, delicada pero crítica, a la nervura verbal de lo que no es, 
de permutaciones de significaciones posibles, sino como conmoción, como desvío, que pone en peligro sus propias estructuras (con cada palabra de cada frase, como decía Foucault), y eso sin garantías de un objetivo o un fin a alcanzar, más allá de esa búsqueda sin objeto ni fin «que los habitantes de las cavernas un día inauguraron sin tradición» (Merleau-Ponty, 1974: 86 - modificado).

«El lenguaje de la crítica, que tiene la ambición de convertir en una verdadera posesión la aprehensión resbaladiza que la literatura nos ofrece de la experiencia» (Merleau-Ponty, 1974: 102), ejerce, en el fondo, la misma potencia que el propio lenguaje poético y está llamado, en esa misma medida, a sumarse a las aventuras de la expresión. Para responder de forma productiva a ese llamado, debe tomar en cuenta la singularidad de cualquier obra de arte, fingir nunca antes haber leído, y considerar los textos en su extraña fecundidad, no como mensajes a ser descifrados, sino como matrices de ideas, esto es, como expresiones cuyo sentido jamás acabaremos de desenvolver, porque nos abren a un mundo del cual no tenemos la llave (Merleau-Ponty, 1974: 101).

\section{NOTAS}

tal como es (Foucault, 1994: 308).

32 | Los artistas, claro, no siempre son conscientes de ese trabajo permanente de refundación, y quizá, como dice Merleau-Ponty, es mejor que sea de esa forma - tal vez no sea malo que el pintor y el escritor no sepan muy bien que están fundando la humanidad» (Merleau-Ponty, 1991: 65).

33 | «El artista lanza su obra como un hombre lanzó la primera palabra, sin saber si ella será algo más que un grito, si ella podrá destacarse del flujo de vida individual donde nace, y presentar, sea a ella misma en su futuro, sea a las mónadas que coexisten con ella, sea a la comunidad abierta de las mónadas futuras, la existencia independiente de un sentido identificable» (Merleau-Ponty, 2004: 139).

$34 \mid$ «El arte no es ni una imitación, ni una fabricación según los deseos del instinto o del buen gusto. Es una operación de expresión» (Merleau-Ponty, 2004: 137).

35| Es en ese sentido que «los primeros dibujos en las paredes de las cavernas definían un campo de investigaciones, postulaban el mundo como a ser pintado o dibujado, y convocaban un futuro indefinido de la pintura» (Merleau-Ponty, 1974: 84). 


\section{Bibliografía citada}

BATAILLE, G. (2013): «Hegel, a morte e o sacrificio», Alea, vol. 15, 2, 389-413.

BLANCHOT, M. (2011): O espaço literário, Rio de Janeiro: Rocco.

DELEUZE, G \& Guattari, F. (1980): Capitalisme et schizophrenie tome 2: Mille plateaux, Paris: Éditions de Minuit.

DELEUZE, G. (1993): Critique et clinique, Paris: Editions de Minuit,.

FOUCAULT, M. (1994): «L'arrière-fable» en Dits et écrits. París: Gallimard.

FOUCAULT, M. (2000): «Linguagem e literatura» en Machado, R., A filosofia e a literatura, Rio de Janeiro: Jorge Zahar Editor.

LOTMAN, I. (1978): A Estrutura do texto artístico, Lisboa: Editorial Estampa.

MERLEAU-PONTY, M. (2004): «A dúvida de Cezanne» en O olho e o espirito, São Paulo: Cosac Naify. MERLEAU-PONTY, M. (1974): «A linguagem indireta» (1952) en O homem e a comunicação. A prosa do mundo, Rio de Janeiro: Edições Bloch.

MERLEAU-PONTY, M. (1991): «A linguagem indireta e as vozes do silêncio», "Sobre a fenomenologia da linguagem» (1951) en Signos, São Paulo: Martin Fontes.

NANCY, J-L. (2015): Pensar a imagem en ALLOA, E. (org.), Belo Horizonte: Autêntica.

NIETZSCHE, F. (2001): «Verdade e Mentira no Sentido Extramoral», Comum, vol. 6, 17. Rio de Janeiro. PROUST, M. (1971): Contre Sainte-Beuve, précédé de Pastiches et Mélanges et suivi de Essais et articles, Paris: Gallimard.

RANCIĖRE, J. (2005): A partilha do sensível, São Paulo: Ed. 34.

SAER, J. J. (2004): El concepto de ficción, Buenos Aires: Seix Barral. 